\title{
RELAÇÕES ENTRE CARACTERES DE PIMENTÃo PROVENIENTES DE SEMENTES COM DIFERENTES NÍVEIS DE QUALIDADE FISIOLÓGICA ${ }^{1}$
}

\author{
RÉLIA RODRIGUES BRUNES ${ }^{2 *}$, ALESSANDRO DAL'COL LÚCIO ${ }^{2}$, MARCOS TOEBE $^{2}$, \\ DIOGO VANDERLEI SCHWERTNER ${ }^{2}$, FERNANDO MACHADO HAESBAERT ${ }^{2}$
}

\begin{abstract}
RESUMO - O objetivo deste trabalho foi identificar as relações entre as variáveis morfológicas e produtivas das plantas de pimentão provenientes de sementes com diferentes níveis de qualidade fisiológica. Os experimentos foram conduzidos em ambiente protegido na Universidade Federal de Santa Maria (UFSM), no delineamento blocos ao acaso, com oito repetições. Os tratamentos consistiram de três lotes de sementes do híbrido Tiberius e um lote da cultivar Rubi Giant nas estações de cultivo primavera-verão e outono-inverno, com diferentes níveis de qualidade fisiológica com base nos testes de germinação e vigor. Foram mensurados os seguintes caracteres (variáveis): altura de planta; altura da primeira bifurcação; diâmetro do caule; diâmetro do caule abaixo da primeira bifurcação aos 50, 70 e 90 dias após o transplantio; peso médio de frutos; produção média de frutos por colheita; produção total; comprimento médio de frutos; e largura média de frutos. A seguir, para cada nível de vigor, foi estimada a matriz de correlação de Pearson, o diagnóstico da multicolinearidade e, posteriormente, a análise de trilha, considerando a produção total de frutos como variável principal. As plantas obtidas a partir de sementes de vigor alto, médio e baixo, com maior diâmetro da primeira bifurcação aos 50 e 90 dias após o transplantio, são mais produtivas na estação de cultivo primavera-verão. No outono-inverno foram verificados coeficientes de correlação e efeitos diretos de baixa magnitude para todos os níveis de vigor, indicando fraca relação de causa e efeito das variáveis explicativas mensuradas sobre a produção total de frutos de pimentão.
\end{abstract}

Palavras-chave: Capsicum annuum L. Análise de trilha. Vigor. Rendimento.

\section{RELATIONSHIPS AMONG TRAITS IN BELL PEPPER DERIVED FROM SEEDS WITH DIFFERENT LEVELS OF PHYSIOLOGICAL QUALITY}

\begin{abstract}
This study aimed to identify the relationship between morphological variables and production variables in bell pepper plants derived from seeds of different physiological levels. The experiments were carried out in a randomized block design with eight replications in a protected setting at Universidade Federal de Santa Maria. Treatments included three lots of hybrid Tiberius seeds and one lot of Rubi Giant seeds during Spring-Winter and Autumn-Winter season with different levels of physiological quality as shown by vigor and germination tests. The following characters (variables) were measured: plant height, first fork height, stem diameter, and stem diameter below the first fork after 50 days, 70 days and 90 days of transplanting, average weight of fruits, average production per harvest, total production, average fruit length, and average width of fruits. Next, for each level of vigor was estimated the correlation matrixes, multicollinearity diagnosis, and then path analysis, considering the total production as the main variable.Plants derived from high-, low- and medium vigor seeds whose first fork diameters were greater after 50 days and 70 days of transplanting are more productive during Spring-Winter seeding. Coefficients of correlation and effect of low magnitude were identified in vigor levels (being high, low, medium, and extremely low) during Autumn-Winter season, indicating a weak relationship between cause and effect of explanatory variables measured on total fruit production of bell pepper.
\end{abstract}

Keywords:Capsicum annuum L. Path analysis.Vigor. Yield.

\footnotetext{
*Autor para correspondência

${ }^{1}$ Recebido para publicação em 15/09/2014; aceito em 05/04/2015.

Parte da Tese de Doutorado em Agronomia do primeiro autor apresentada à UFSM, Santa Maria (RS).

${ }^{2}$ Departamento de Fitotecnia, Centro de Ciências Rurais, UFSM, 97105-900, Santa Maria (RS), Brasil; reliabrunes@gmail.com.
}

Revista Caatinga, Mossoró, v. 28, n. 3, p. 108 - 118, jul. - set., 2015 


\section{INTRODUÇÃO}

A qualidade fisiológica de sementes, determinada pela germinação e vigor, é um dos aspectos mais importantes para se alcançar o sucesso da lavoura. Em culturas olerícolas acredita-se que a qualidade fisiológica pode influenciar na produção de mudas e nos estádios subsequentes das plantas a campo. Mudas com crescimento desuniforme e/ou debilitadas poderão originar plantas com ciclo mais longo (KIKUTI; MARCOS FILHO, 2007), gerando maior variabilidade experimental na lavoura devido a desuniformidade na maturação dos frutos. Esta condição pode contribuir para a redução da produção obtida entre as colheitas e a perda da qualidade do produto comercial.

Embora pesquisas destaquem a importância do vigor das sementes no crescimento inicial de plântulas, os efeitos da qualidade fisiológica das sementes sobre os componentes do rendimento ainda são controversos. Em estudo desenvolvido por Gamiely et al. (1990) verificou-se maior produtividade de cebola quando foram utilizadas sementes mais vigorosas. Em contrapartida, Kikuti e Marcos Filho (2007) e Dantas e Torres (2010) evidenciaram nas culturas de couve-flor e rúcula, respectivamente, o vigor das sementes como fator determinante durante o desenvolvimento inicial das plantas, sendo atenuada com o decorrer do ciclo da cultura, não influenciando na produção final.

Estudos nesse campo são importantes para informar ao produtor a necessidade de adequar a produção para minimizar a variação entre sementes do mesmo lote, bem como a importância de se usarem sementes de alta qualidade. Soma-se a isso o elevado preço das sementes existentes no mercado e o alto grau de tecnologia envolvido na produção comercial de olerícolas. Dessa forma, com o incremento do plantio de olerícolas e a demanda crescente por produtos de melhor qualidade torna-se imprescindível a realização de pesquisas que objetivem o desenvolvimento de técnicas e recomendações agronômicas visando o aumento da produtividade e redução de custos ao produtor.

Mediante a isso, o estudo das relações lineares entre caracteres tem aplicações em praticamente todas as áreas de pesquisa. Entre as técnicas utilizadas em estudos de associação entre caracteres a análise de correlação simples mede o grau da correlação e sua direção (positiva ou negativa) entre duas variáveis quantitativas. Todavia, a quantificação e a interpretação da magnitude das correlações simples não indicam efeitos diretos e indiretos e relações de causa e efeito entre variáveis, sugerindo a utilização de técnicas complementares mais informativas (CRUZ; REGAZZI, 1997; CRUZ; CARNEIRO, 2006). Com essa finalidade, Wright $(1921 ; 1923)$ propôs a análise de trilha (path analysis), a qual consiste no desdobramento do coeficiente de correlação simples em efeitos diretos e indiretos de variáveis explicativas sobre a variável principal, cujas estimativas são obtidas por meio de equações de regressão previamente padronizadas (CRUZ; REGAZZI, 1997; CRUZ; CARNEIRO, 2006), permitindo a identificação de relações de causa e efeito entre variáveis. Essa técnica de análise é comumente utilizada em pesquisas de melhoramento genético via seleção indireta em diversas culturas agrícolas, como em milho (TOEBE; CARGNELUTTI FILHO, 2013) e maracujazeiroazedo (LÚCIO et al., 2013). Além disso, seu uso pode ser extrapolado para outras áreas de investigação, mostrando o grau de relação entre caracteres e estatísticas em condições de planejamento e condução de experimentos, como verificado por Lúcio et al. (2006) em pimentão e por Cargnelutti Filho et al. (2011) em feijão.

O presente trabalho teve como objetivo identificar as relações entre as variáveis morfológicas e produtivas das plantas de pimentão provenientes de sementes com diferentes níveis de qualidade fisiológica.

\section{MATERIAL E MÉTODOS}

Foram conduzidos dois experimentos de pimentão em ambiente protegido na Universidade Fe-

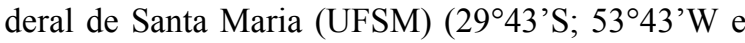
$95 \mathrm{~m}$ de altitude), Santa Maria (RS), sendo o primeiro experimento conduzido na estação de cultivo primavera-verão de 2010/11 (transplantio de mudas em 07/10/2010) e o segundo experimento conduzido na estação outono-inverno de 2011 (transplantio de mudas em 18/03/2011).

Para cada cultivo sementes do híbrido Tiberius foram envelhecidas artificialmente (EA, procedimento tradicional), conforme Marcos Filho (1999), objetivando-se atingir diferentes níveis de perda de vigor (SANTOS et al., 2004; GOULART; TILLMANN, 2007). As sementes foram colocadas em caixas gerbox contendo $40 \mathrm{~mL}$ de água destilada e mantidas em estufa incubadora do tipo BOD, regulada a $41^{\circ} \mathrm{C}$ por períodos de 24,48 e 72 horas. Foram realizados os testes de germinação, primeira contagem da germinação, teste de emergência em areia (BRASIL, 2009) e o índice de velocidade de emergência (MAGUIRE, 1962). A seguir, os lotes foram classificados como sendo de vigor alto, médio, baixo ou muito baixo (Tabela 1).

Os cultivos foram realizados em ambiente protegido, qual seja: estufa de cobertura plástica. Os tratamentos foram distribuídos no delineamento experimental de blocos ao acaso com oito repetições, sendo que cada unidade experimental foi constituída por 13 plantas no sentido da fileira de cultivo, totalizando 52 plantas por fileira ou bloco (13 plantas por parcela $\times 4$ tratamentos/bloco). Os tratamentos con- 
sistiram de três lotes de sementes de pimentão do Híbrido Tiberius e um lote de semente da cultivar Rubi Giant com diferentes níveis de qualidade fisio- lógica conforme os testes de germinação e vigor (Tabela 1).

Tabela 1. Testes de germinação (G), primeira contagem da germinação (PCG), emergência de plântulas em areia (TA) e índice de velocidade de emergência (IVE) em sementes de pimentão do híbrido Tiberius e da cultivar Rubi.

\begin{tabular}{cccccc}
\hline \multirow{2}{*}{ Lote $^{1}$} & \multicolumn{5}{c}{ Primavera-verão } \\
\cline { 2 - 6 } & G (\%) & PCG (\%) & TA (\%) & IVE & Vigor \\
\hline LO & 91 & 81 & --- & --- & Alto \\
EA 48h & 86 & 74 & --- & --- & Médio \\
EA 72h & 80 & 62 & --- & --- & Baixo \\
RG & 76 & 55 & --- & --- & Muito baixo \\
\hline LO & 94 & & Outono-inverno & Alto \\
EA 24h & 89 & 85 & 98 & 6,81 & Médio \\
EA 72h & 82 & 72 & 88 & 5,90 & Baixo \\
RG & 74 & 69 & 84 & 5,20 & Muito baixo \\
\hline
\end{tabular}

${ }^{1}$ LO: lote original do híbrido Tiberius; EA 24h, 48h, 72h: sementes do híbrido Tiberius envelhecidas artificialmente nos períodos de 24, 48 e 72 horas, respectivamente; e RG: lote original da cultivar Rubi Giant.

As mudas de cada tratamento foram transplantadas na estufa de cobertura plástica, as quais apresentaram de seis a oito folhas definitivas e dispostas em oito fileiras de cultivo de $16 \mathrm{~m}$ de comprimento. A estufa apresentava dimensões de 20 metros de comprimento no sentido Norte-Sul e 10 metros de largura, pé direito de 2,0 metros e altura central de 3,5 metros com estrutura na forma de arco pampeano, coberta com filme de PeBD 100 micra. Utilizouse espaçamento de $1,00 \mathrm{~m}$ entre as fileiras (camalhões cobertos com mulching - plástico opaco preto de PeBD 35 micra) e 0,30 m entre plantas. As necessidades hídricas da cultura foram supridas via irrigação por gotejamento e a adubação de plantio com $130 \mathrm{kgha}^{-1}$ de $\mathrm{N}, 70 \mathrm{~kg} \mathrm{ha}^{-1} \mathrm{P}_{2} \mathrm{O}_{5}$ e $230 \mathrm{~kg} \mathrm{ha}^{-1}$ de $\mathrm{K}_{2} \mathrm{O}$ nas formas de ureia, superfosfato simples e cloreto de potássio, respectivamente. Durante o desenvolvimento das plantas foram selecionadas e eliminadas hastes acima da primeira bifurcação, bem como as flores da primeira bifurcação, sendo mantidas apenas quatro hastes por planta a serem conduzidas via tutoramento. O ponto de colheita foi caracterizado pela coloração azulada na base do fruto, sendo que no total foram realizadas cinco colheitas na estação primavera-verão e quatro colheitas na estação outono-inverno.

Em cada estação de cultivo foram mensurados os seguintes caracteres: altura de planta (AP, em $\mathrm{cm}$ ), mensurada do colo da planta até a extremidade da ramificação da maior haste, e altura da primeira bifurcação (AB, em cm), mensurada do colo da planta até a primeira bifurcação utilizando fita métrica; diâmetro do caule acima do colo da planta (DC, em $\mathrm{cm}$ ) e diâmetro do caule abaixo da primeira bifurcação (DB, em cm), utilizando paquímetro universal com resolução de $0,05 \mathrm{~mm}$; peso médio de frutos (PMF, em g), obtido pelo quociente entre o peso total dos frutos colhidos dentro de cada unidade experimental em cada colheita e dividido pelo número de frutos colhidos em cada unidade experimental; produção média de frutos por colheita (PMC, em g planta $^{-1}$ ), obtido pelo quociente entre o peso total de frutos de cada planta pelo número de colheitas realizadas; produção total (PT, em g), obtida por meio do somatório do peso de frutos obtidos nas colheitas; e comprimento médio de frutos $(\mathrm{CMF}$, em $\mathrm{cm})$ e largura média de frutos (LMF, em $\mathrm{cm}$ ), com o uso de paquímetro universal com resolução de $0,05 \mathrm{~mm}$. As mensurações de AP, AB, DC e DB foram realizadas aos 50, 70 e 90 dias após o transplantio (DAT). E as medidas das variáveis convertidas de $\mathrm{mm}$ para $\mathrm{cm}$ visando a homogeneização dos resultados com as demais variáveis.

A partir desses dados, em cada tratamento (nível de vigor) e estação de cultivo (primaveraverão ou outono-inverno) foi estimada a matriz de correlação de Pearson e realizado o diagnóstico da multicolinearidade entre as variáveis explicativas, a fim de manter na análise de trilha apenas variáveis com baixo grau de multicolinearidade. Como critério de decisão, considerou-se multicolinearidade fraca entre as variáveis explicativas, quando o número de condição (NC) foi menor que 100 , conforme classificação de Montgomery e Peck (1982). Nos casos em que a multicolinearidade foi maior ou igual a 100 foram eliminadas variáveis explicativas e realizado o 
diagnóstico de multicolinearidade novamente, até que o NC foi menor que 100. A seguir, com as variáveis explicativas que não foram eliminadas, fora realizada a análise de trilha (path analysis), conforme descrito por Cruz e Regazzi (1997) e Cruz e Carneiro (2006), considerando a produção total de frutos de pimentão (PT) como variável dependente e as demais variáveis como sendo variáveis explicativas. As análises estatísticas foram realizadas com auxílio do programa Genes (CRUZ, 2013), considerando 5\% de probabilidade de erro em todas as análises.

\section{RESULTADOS E DISCUSSÃO}

Os coeficientes de correlação linear entre a variável produção total $(\mathrm{PT})$ e as demais variáveis foram significativos para a maioria dos casos na estação primavera-verão, independentemente do nível de vigor (Tabelas 2 a 5). Também foram constatadas correlações positivas e significativas de PT com AP50, AP70, AP90, DC50, DC70, DC90, DB50, DB70, DB90 e PMF nas plantas obtidas a partir de sementes de alto vigor. Dentre estas as maiores correlações foram de PT com DB50 e DB90, de, respectivamente, 0,60 e 0,57 (Tabela 2). Assim, plantas originadas de sementes de vigor alto que apresentam maior DB aos 50 e 90 DAT podem ser mais produtivas.

Tabela 2. Estimativa dos efeitos diretos e indiretos das variáveis explicativas sobre a produção total de frutos de pimentão (PT) provenientes de plantas originadas de sementes de vigor alto cultivadas em ambiente protegido na estação primavera-verão.

\begin{tabular}{|c|c|c|c|c|c|c|c|c|c|c|c|c|c|c|}
\hline \multirow{2}{*}{ Variáveis $^{1}$} & P50 & 0 & AP90 & $\mathrm{AB} 50$ & AB90 & DC50 & $\mathrm{C} 70$ & C90 & DB50 & DB70 & DB90 & PMF & $\mathrm{CMF}$ & LMF \\
\hline & \multicolumn{14}{|c|}{ Efeito indireto } \\
\hline Via AP50 & & $-0,10$ & $-0,08$ & $-0,01$ & 0,00 & $-0,08$ & $-0,09$ & $-0,11$ & $-0,10$ & $-0,09$ & $-0,07$ & $-0,06$ & $-0,02$ & $-0,02$ \\
\hline Via AP70 & 0,03 & & 0,03 & 0,01 & 0,01 & 0,01 & 0,02 & 0,02 & 0,02 & 0,02 & 0,02 & 0,01 & 0,00 & 0,01 \\
\hline Via AP90 & 0,06 & 0,10 & & 0,02 & 0,02 & 0,03 & 0,05 & 0,05 & 0,05 & 0,05 & 0,05 & 0,02 & 0,01 & 0,03 \\
\hline Via AB50 & 0,01 & 0,02 & 0,02 & & 0,09 & $-0,01$ & 0,00 & 0,00 & 0,01 & 0,02 & 0,02 & 0,00 & $-0,03$ & $-0,02$ \\
\hline Via AB90 & 0,00 & $-0,01$ & 0,00 & $-0,02$ & & 0,00 & 0,00 & 0,00 & 0,00 & 0,00 & 0,00 & 0,00 & 0,00 & 0,00 \\
\hline Via DC50 & 0,01 & 0,01 & 0,01 & 0,00 & 0,00 & & 0,02 & 0,01 & 0,01 & 0,01 & 0,01 & 0,01 & 0,00 & 0,01 \\
\hline Via DC70 & 0,15 & 0,12 & 0,11 & 0,01 & 0,04 & 0,22 & & 0,23 & 0,16 & 0,19 & 0,13 & 0,10 & 0,04 & 0,05 \\
\hline & 00 & $-0,04$ & $-0,04$ & 0,00 & $-0,01$ & $-0,08$ & $-0,10$ & & $-0,07$ & $-0,07$ & $-0,05$ & $-0,04$ & $-0,01$ & $-0,02$ \\
\hline Via I & 0,22 & 0,19 & 0,14 & 0,03 & 0,04 & 0,23 & 0,20 & 0,21 & & 0,24 & 0,23 & 0,10 & 0,03 & 0,07 \\
\hline Via DB70 & $-0,01$ & 0,00 & 0,00 & 0,00 & 0,00 & $-0,01$ & $-0,01$ & $-0,01$ & $-0,01$ & & $-0,01$ & 0,00 & 0,00 & 0,00 \\
\hline Via DB90 & 0,08 & 0,09 & 0,08 & 0,03 & 0,03 & 0,09 & 0,09 & 0,09 & 0,13 & 0,14 & & 0,05 & 0,03 & 0,06 \\
\hline Via PMF & 0,02 & 0,01 & 0,01 & 0,00 & 0,00 & 0,02 & 0,02 & 0,02 & 0,02 & 0,02 & 0,02 & & 0,02 & 0,02 \\
\hline Via CMF & 0,02 & 0,01 & 0,01 & $-0,03$ & $-0,02$ & 0,01 & 0,01 & 0,01 & 0,01 & 0,00 & 0,02 & 0,03 & & 0,01 \\
\hline Via LMF & 0,00 & $-0,01$ & $-0,01$ & 0,00 & 0,00 & $-0,01$ & $-0,01$ & $-0,01$ & $-0,01$ & 0,00 & $-0,01$ & $-0,01$ & 0,00 & \\
\hline Efeito direto & $-0,18$ & 0,05 & 0,14 & 0,12 & $-0,03$ & 0,02 & 0,30 & $-0,12$ & 0,38 & $-0,01$ & 0,21 & 0,07 & 0,11 & $-0,03$ \\
\hline Correlação ${ }^{3}$ & $0,34^{*}$ & $0,43^{*}$ & $0,40^{*}$ & $0,16^{\mathrm{ns}}$ & $0,18^{\text {ns }}$ & $0,46^{*}$ & $0,51^{*}$ & $0,39^{*}$ & $0,60^{*}$ & $0,52^{*}$ & $0,57^{*}$ & $0,29^{*}$ & $0,19^{\mathrm{ns}}$ & $0,17^{\text {ns }}$ \\
\hline $\mathrm{R}^{2}$ & 0,52 & & & & & & & & & & & & & \\
\hline
\end{tabular}

${ }^{1}$ AP50, AP70 e AP90: altura de plantas aos 50, 70 e 90 dias após o transplantio (DAT), respectivamente; AB50 e AB90: altura da primeira bifurcação aos 50 e 90 dias após o transplantio (DAT), respectivamente; DC50, DC70 e DC90: diâmetro do caule aos 50, 70 e 90 dias após o transplantio (DAT), respectivamente; DB50, DB70 e DB90: diâmetro abaixo da primeira bifurcação aos 50, 70 e 90 dias após o transplantio (DAT), respectivamente; PMF: peso médio de frutos; CMF: comprimento médio de frutos; e LMF: largura média de frutos.

3 :ns $\mathrm{e}^{*}$, significativo a $5 \%$ de probabilidade pelo teste $\mathrm{t}$, respectivamente.

${ }^{2}$ Coeficiente de determinação.

Em plantas originadas de sementes de vigor médio as maiores correlações foram constatadas de AP70 e DB90 com PT, de, respectivamente, 0,54 e
0,50. Destacam-se também correlações positivas e significativas de PT com AP90 $(0,47)$, DB50 $(0,40)$ e DB70 $(0,43)$ (Tabela 3). 
Tabela 3. Estimativa dos efeitos diretos e indiretos das variáveis explicativas sobre a produção total de frutos de pimentão $(\mathrm{PT})$ provenientes de plantas originadas de sementes de vigor médio cultivadas em ambiente protegido na estação primavera-verão.

\begin{tabular}{|c|c|c|c|c|c|c|c|c|c|c|c|c|c|c|}
\hline \multirow{2}{*}{ Variáveis ${ }^{1}$} & AP50 & AP70 & AP90 & AB50 & AB90 & DC50 & DC70 & DC90 & DB50 & DB70 & DB90 & PMF & $\mathrm{CMF}$ & LMF \\
\hline & \multicolumn{14}{|c|}{ Efeito indireto } \\
\hline Via AP50 & & $-0,10$ & $-0,08$ & $-0,01$ & 0,00 & $-0,08$ & $-0,09$ & $-0,11$ & $-0,10$ & $-0,09$ & $-0,07$ & $-0,06$ & $-0,02$ & $-0,02$ \\
\hline Via AP70 & 0,03 & & 0,03 & 0,01 & 0,01 & 0,01 & 0,02 & 0,02 & 0,02 & 0,02 & 0,02 & 0,01 & 0,00 & 0,01 \\
\hline Via AP90 & 0,06 & 0,10 & & 0,02 & 0,02 & 0,03 & 0,05 & 0,05 & 0,05 & 0,05 & 0,05 & 0,02 & 0,01 & 0,03 \\
\hline Via AB50 & 0,01 & 0,02 & 0,02 & & 0,09 & $-0,01$ & 0,00 & 0,00 & 0,01 & 0,02 & 0,02 & 0,00 & $-0,03$ & $-0,02$ \\
\hline Via AB90 & 0,00 & $-0,01$ & 0,00 & $-0,02$ & & 0,00 & 0,00 & 0,00 & 0,00 & 0,00 & 0,00 & 0,00 & 0,00 & 0,00 \\
\hline Via DC50 & 0,01 & 0,01 & 0,01 & 0,00 & 0,00 & & 0,02 & 0,01 & 0,01 & 0,01 & 0,01 & 0,01 & 0,00 & 0,01 \\
\hline Via DC70 & 0,15 & 0,12 & 0,11 & 0,01 & 0,04 & 0,22 & & 0,23 & 0,16 & 0,19 & 0,13 & 0,10 & 0,04 & 0,05 \\
\hline Via DC90 & $-0,08$ & $-0,04$ & $-0,04$ & 0,00 & $-0,01$ & $-0,08$ & $-0,10$ & & $-0,07$ & $-0,07$ & $-0,05$ & $-0,04$ & $-0,01$ & $-0,02$ \\
\hline Via DB50 & 0,22 & 0,19 & 0,14 & 0,03 & 0,04 & 0,23 & 0,20 & 0,21 & & 0,24 & 0,23 & 0,10 & 0,03 & 0,07 \\
\hline Via DB70 & $-0,01$ & 0,00 & 0,00 & 0,00 & 0,00 & $-0,01$ & $-0,01$ & $-0,01$ & $-0,01$ & & $-0,01$ & 0,00 & 0,00 & 0,00 \\
\hline Via DB90 & 0,08 & 0,09 & 0,08 & 0,03 & 0,03 & 0,09 & 0,09 & 0,09 & 0,13 & 0,14 & & 0,05 & 0,03 & 0,06 \\
\hline Via PMF & 0,02 & 0,01 & 0,01 & 0,00 & 0,00 & 0,02 & 0,02 & 0,02 & 0,02 & 0,02 & 0,02 & & 0,02 & 0,02 \\
\hline Via CMF & 0,02 & 0,01 & 0,01 & $-0,03$ & $-0,02$ & 0,01 & 0,01 & 0,01 & 0,01 & 0,00 & 0,02 & 0,03 & & 0,01 \\
\hline Via LMF & 0,00 & $-0,01$ & $-0,01$ & 0,00 & 0,00 & $-0,01$ & $-0,01$ & $-0,01$ & $-0,01$ & 0,00 & $-0,01$ & $-0,01$ & 0,00 & \\
\hline Efeito direto & $-0,18$ & 0,05 & 0,14 & 0,12 & $-0,03$ & 0,02 & 0,30 & $-0,12$ & 0,38 & $-0,01$ & 0,21 & 0,07 & 0,11 & $-0,03$ \\
\hline Correlação $^{3}$ & $0,34^{*}$ & $0,43^{*}$ & $0,40^{*}$ & $0,16^{\mathrm{ns}}$ & $0,18^{\mathrm{ns}}$ & $0,46^{*}$ & $0,51^{*}$ & $0,39^{*}$ & $0,60^{*}$ & $0,52^{*}$ & $0,57^{*}$ & $0,29^{*}$ & $0,19^{\mathrm{ns}}$ & $0,17^{\text {ns }}$ \\
\hline $\mathrm{R}^{2}$ & 0,52 & & & & & & & & & & & & & \\
\hline
\end{tabular}

${ }^{1}$ AP50, AP70 e AP90: altura de plantas aos 50, 70 e 90 dias após o transplantio (DAT), respectivamente; AB50 e AB90: altura da primeira bifurcação aos 50 e 90 dias após o transplantio (DAT), respectivamente; DC50, DC70 e DC90: diâmetro do caule aos 50, 70 e 90 dias após o transplantio (DAT), respectivamente; DB50, DB70 e DB90: diâmetro abaixo da primeira bifurcação aos 50, 70 e 90 dias após o transplantio (DAT), respectivamente; PMF: peso médio de frutos; CMF: comprimento médio de frutos; e LMF: largura média de frutos.

${ }^{3}:^{\text {ns }}$ e ${ }^{*}$, significativo a $5 \%$ de probabilidade pelo teste $\mathrm{t}$, respectivamente.

${ }^{2}$ Coeficiente de determinação.

Para o vigor baixo, maiores magnitudes de correlação foram verificadas de PT com DC50 e DB50, de, respectivamente, 0,46 e 0,44 (Tabela 4).

Já no vigor muito baixo, DB50 $(0,54)$, DB70 $(0,54)$, DC50 $(0,51)$, DC90 $(0,51)$ e AP70 $(0,50)$ apresentaram maiores correlações com PT (Tabela 5). Em estudo desenvolvido por Lúcio et al. (2006) os autores constataram correlação positiva e significativa entre a produção total de pimentão e as variáveis número de frutos colhidos, peso médio de frutos por colheita, peso médio de frutos e desvio padrão entre o número de colheitas realizadas. Além disso, observaram alta correlação com comprimento e largura média de frutos, relação entre comprimento e largura de frutos, diâmetro de caule na altura do colo, diâmetro de caule na altura da primeira bifurcação, altura da primeira bifurcação e altura da planta nas estações primavera-verão e outono-inverno.

Em todos os níveis de vigor da estação de cultivo primavera-verão o diagnóstico da multicolinearidade foi classificado como moderada a severa, com valores entre $135 \leq \mathrm{NC} \leq 416$. No outonoinverno somente o vigor alto apresentou $\mathrm{NC} \geq 100$.
Conforme Carvalho (1995), em presença de multicolinearidade as variâncias associadas aos estimadores dos coeficientes de trilha podem atingir valores demasiadamente elevados, tornando-os coeficientes pouco confiáveis. Além disso, as estimativas dos parâmetros podem assumir valores absurdos ou sem nenhuma coerência com o fenômeno biológico estudado. Para atenuar o grau da multicolinearidade optou-se pela eliminação de variáveis explicativas altamente correlacionadas. Em todos os níveis de vigor nas duas estações de cultivo a eliminação das variáveis altura da primeira bifurcação aos 70 dias após o transplantio (AB70) e produção média de frutos por colheita (PMC) foi suficiente para reduzir o NC para valores inferiores a 100 , permitindo a realização adequada da análise de trilha. Optou-se pela eliminação destas variáveis também nas situações em que o $\mathrm{NC}$ inicial, com todas as variáveis explicativas, foi menor que 100 , com fim a possibilitar o desdobramento dos efeitos diretos e indiretos de um mesmo conjunto de variáveis explicativas sobre a produção total, em todos os níveis de vigor, nas duas estações de cultivo. 
Tabela 4. Estimativa dos efeitos diretos e indiretos das variáveis explicativas sobre a produção total de frutos de pimentão (PT) provenientes de plantas originadas de sementes de vigor baixo cultivada em ambiente protegido na estação primavera-verão.

\begin{tabular}{|c|c|c|c|c|c|c|c|c|c|c|c|c|c|c|}
\hline \multirow{2}{*}{ Variáveis ${ }^{1}$} & AP50 & AP70 & AP90 & AB50 & AB90 & DC50 & DC70 & DC90 & DB50 & DB70 & DB90 & PMF & $\mathrm{CMF}$ & LMF \\
\hline & \multicolumn{14}{|c|}{ Efeito indireto } \\
\hline Via AP50 & & $-0,10$ & $-0,08$ & $-0,01$ & 0,00 & $-0,08$ & $-0,09$ & $-0,11$ & $-0,10$ & $-0,09$ & $-0,07$ & $-0,06$ & $-0,02$ & $-0,02$ \\
\hline Via AP70 & 0,03 & & 0,03 & 0,01 & 0,01 & 0,01 & 0,02 & 0,02 & 0,02 & 0,02 & 0,02 & 0,01 & 0,00 & 0,01 \\
\hline Via AP90 & 0,06 & 0,10 & & 0,02 & 0,02 & 0,03 & 0,05 & 0,05 & 0,05 & 0,05 & 0,05 & 0,02 & 0,01 & 0,03 \\
\hline Via AB50 & 0,01 & 0,02 & 0,02 & & 0,09 & $-0,01$ & 0,00 & 0,00 & 0,01 & 0,02 & 0,02 & 0,00 & $-0,03$ & $-0,02$ \\
\hline Via AB90 & 0,00 & $-0,01$ & 0,00 & $-0,02$ & & 0,00 & 0,00 & 0,00 & 0,00 & 0,00 & 0,00 & 0,00 & 0,00 & 0,00 \\
\hline Via DC50 & 0,01 & 0,01 & 0,01 & 0,00 & 0,00 & & 0,02 & 0,01 & 0,01 & 0,01 & 0,01 & 0,01 & 0,00 & 0,01 \\
\hline Via DC70 & 0,15 & 0,12 & 0,11 & 0,01 & 0,04 & 0,22 & & 0,23 & 0,16 & 0,19 & 0,13 & 0,10 & 0,04 & 0,05 \\
\hline Via DC90 & $-0,08$ & $-0,04$ & $-0,04$ & 0,00 & $-0,01$ & $-0,08$ & $-0,10$ & & $-0,07$ & $-0,07$ & $-0,05$ & $-0,04$ & $-0,01$ & $-0,02$ \\
\hline Via DB50 & 0,22 & 0,19 & 0,14 & 0,03 & 0,04 & 0,23 & 0,20 & 0,21 & & 0,24 & 0,23 & 0,10 & 0,03 & 0,07 \\
\hline Via DB70 & $-0,01$ & 0,00 & 0,00 & 0,00 & 0,00 & $-0,01$ & $-0,01$ & $-0,01$ & $-0,01$ & & $-0,01$ & 0,00 & 0,00 & 0,00 \\
\hline Via DB90 & 0,08 & 0,09 & 0,08 & 0,03 & 0,03 & 0,09 & 0,09 & 0,09 & 0,13 & 0,14 & & 0,05 & 0,03 & 0,06 \\
\hline Via PMF & 0,02 & 0,01 & 0,01 & 0,00 & 0,00 & 0,02 & 0,02 & 0,02 & 0,02 & 0,02 & 0,02 & & 0,02 & 0,02 \\
\hline Via CMF & 0,02 & 0,01 & 0,01 & $-0,03$ & $-0,02$ & 0,01 & 0,01 & 0,01 & 0,01 & 0,00 & 0,02 & 0,03 & & 0,01 \\
\hline Via LMF & 0,00 & $-0,01$ & $-0,01$ & 0,00 & 0,00 & $-0,01$ & $-0,01$ & $-0,01$ & $-0,01$ & 0,00 & $-0,01$ & $-0,01$ & 0,00 & \\
\hline Efeito direto & $-0,18$ & 0,05 & 0,14 & 0,12 & $-0,03$ & 0,02 & 0,30 & $-0,12$ & 0,38 & $-0,01$ & 0,21 & 0,07 & 0,11 & $-0,03$ \\
\hline Correlação $^{3}$ & $0,34^{*}$ & $0,43^{*}$ & $0,40^{*}$ & $0,16^{\mathrm{ns}}$ & $0,18^{\mathrm{ns}}$ & $0,46^{*}$ & $0,51^{*}$ & $0,39^{*}$ & $0,60^{*}$ & $0,52^{*}$ & $0,57^{*}$ & $0,29^{*}$ & $0,19^{\text {ns }}$ & $0,17^{\mathrm{ns}}$ \\
\hline $\mathrm{R}^{2}$ & 0,52 & & & & & & & & & & & & & \\
\hline
\end{tabular}

${ }^{1}$ AP50, AP70 e AP90: altura de plantas aos 50, 70 e 90 dias após o transplantio (DAT), respectivamente; AB50 e AB90: altura da primeira bifurcação aos 50 e 90 dias após o transplantio (DAT), respectivamente; DC50, DC70 e DC90: diâmetro do caule aos 50, 70 e 90 dias após o transplantio (DAT), respectivamente; DB50, DB70 e DB90: diâmetro abaixo da primeira bifurcação aos 50, 70 e 90 dias após o transplantio (DAT), respectivamente; PMF: peso médio de frutos; CMF: comprimento médio de frutos; e LMF: largura média de frutos.

3:ns $\mathrm{e}^{*}$, significativo a $5 \%$ de probabilidade pelo teste t, respectivamente.

${ }^{2}$ Coeficiente de determinação.

Tabela 5. Estimativa dos efeitos diretos e indiretos das variáveis explicativas sobre a produção total de frutos de pimentão (PT) provenientes de plantas originadas de sementes de vigor muito baixo cultivadas em ambiente protegido na estação primavera-verão.

\begin{tabular}{|c|c|c|c|c|c|c|c|c|c|c|c|c|c|c|}
\hline \multirow{2}{*}{ Variáveis ${ }^{1}$} & 50 & $\mathrm{P} 70$ & AP90 & $\mathrm{AB} 50$ & $\mathrm{AB} 90$ & DC50 & DC70 & DC90 & DB50 & DB70 & DB90 & PMF & $\mathrm{CMF}$ & LMF \\
\hline & \multicolumn{14}{|c|}{ Efeito indireto } \\
\hline Via & & $-0,06$ & $-0,06$ & $-0,03$ & $-0,02$ & $-0,05$ & $-0,05$ & $-0,05$ & $-0,06$ & $-0,03$ & $-0,03$ & $-0,02$ & 0,00 & 0,00 \\
\hline Via AP70 & 0,21 & & 0,23 & 0,13 & 0,11 & 0,13 & 0,13 & 0,14 & 0,14 & 0,11 & 0,11 & 0,09 & 0,01 & 0,03 \\
\hline Via AP90 & $-0,10$ & $-0,13$ & & $-0,07$ & $-0,05$ & $-0,07$ & $-0,07$ & $-0,08$ & $-0,07$ & $-0,06$ & $-0,07$ & $-0,06$ & $-0,01$ & $-0,02$ \\
\hline Via AB50 & 0,04 & 0,05 & 0,05 & & 0,08 & 0,02 & 0,04 & 0,04 & 0,02 & 0,03 & 0,02 & 0,03 & 0,00 & 0,01 \\
\hline Via $A B 90$ & 0,00 & 0,00 & 0,00 & $-0,01$ & & 0,00 & 0,00 & 0,00 & 0,00 & 0,00 & 0,00 & 0,00 & 0,00 & 0,00 \\
\hline Via DC50 & 0,11 & 0,08 & 0,07 & 0,04 & 0,01 & & 0,12 & 0,12 & 0,13 & 0,08 & 0,07 & 0,04 & 0,02 & 0,04 \\
\hline & $-0,09$ & $-0,07$ & $-0,07$ & $-0,06$ & $-0,03$ & $-0,11$ & & $-0,12$ & $-0,10$ & $-0,09$ & $-0,07$ & $-0,05$ & $-0,02$ & $-0,03$ \\
\hline Via DC90 & 0,03 & 0,03 & 0,03 & 0,02 & 0,01 & 0,04 & 0,05 & & 0,04 & 0,04 & 0,03 & 0,01 & 0,01 & 0,01 \\
\hline Via D & 0,16 & 0,11 & 0,09 & 0,04 & $-0,01$ & 0,17 & 0,15 & 0,14 & & 0,13 & 0,09 & 0,05 & 0,00 & 0,04 \\
\hline & 0 , & 0,07 & 0,07 & 0,04 & 0,01 & 0,09 & 0,10 & 0,10 & 0,10 & & 0,11 & 0,03 & 0,01 & 0,05 \\
\hline Via DB90 & 0,05 & 0,06 & 0,07 & 0,04 & 0,02 & 0,06 & 0,07 & 0,09 & 0,07 & 0,10 & & 0,01 & 0,03 & 0,02 \\
\hline Via PMF & 0,08 & 0,11 & 0,13 & 0,09 & 0,05 & 0,07 & 0,10 & 0,08 & 0,07 & 0,06 & 0,02 & & 0,02 & 0,17 \\
\hline Via CMF & 0,00 & 0,00 & 0,00 & 0,00 & 0,00 & 0,00 & 0,00 & 0,00 & 0,00 & 0,00 & $-0,01$ & 0,00 & & 0,00 \\
\hline Via LMF & 0,00 & 0,00 & 0,00 & 0,00 & 0,00 & 0,01 & 0,01 & 0,00 & 0,01 & 0,01 & 0,00 & 0,02 & 0,00 & \\
\hline Efeito direto & $-0,08$ & 0,26 & $-0,15$ & 0,10 & $-0,01$ & 0,16 & $-0,15$ & 0,05 & 0,21 & 0,16 & 0,15 & 0,31 & $-0,03$ & 0,03 \\
\hline Correlação $^{3}$ & $0,46^{*}$ & $0,50^{*}$ & $0,46^{*}$ & $0,33^{*}$ & $0,17^{\mathrm{ns}}$ & $0,51^{*}$ & $0,49^{*}$ & $0,51^{*}$ & $0,54^{*}$ & $0,54^{*}$ & $0,45^{*}$ & $0,46^{*}$ & $0,05^{\text {ns }}$ & $0,35^{*}$ \\
\hline $\mathrm{R}^{2}$ & 0,51 & & & & & & & & & & & & & \\
\hline
\end{tabular}

${ }^{1} \mathrm{AP50}$, AP70 e AP90: altura de plantas aos 50, 70 e 90 dias após o transplantio (DAT), respectivamente; AB50 e AB90: altura da primeira bifurcação aos 50 e 90 dias após o transplantio (DAT), respectivamente; DC50, DC70 e DC90: diâmetro do caule aos 50, 70 e 90 dias após o transplantio (DAT), respectivamente; DB50, DB70 e DB90: diâmetro abaixo da primeira bifurcação aos 50, 70 e 90 dias após o transplantio (DAT), respectivamente; PMF: peso médio de frutos; CMF: comprimento médio de frutos; e LMF: largura média de frutos. ${ }^{3}$ : ns $\mathrm{e}^{*}$, significativo a $5 \%$ de probabilidade pelo teste t, respectivamente.

${ }^{2}$ Coeficiente de determinação. 
$\mathrm{Na}$ análise de trilha, a maioria das variáveis analisadas apresentou efeito direto de magnitude inferior ao coeficiente de correlação sobre PT, o que demonstrou existirem outras características influenciando indiretamente tanto em magnitude quanto no sentido da correlação (Tabelas 2 a 5). Para fins de melhoramento tal situação dificulta a seleção isolada de um caractere visando a produção total de frutos de pimentão.

Em plantas originadas de sementes de vigor alto, a maior correlação $(0,60)$ e o maior efeito direto foi observado de DB50 $(0,38)$ sobre a produção total de frutos de pimentão (PT). Em função de DB50 apresentar alto coeficiente de correlação e efeito direto de mesma direção sobre a produção total pode -se inferir que essa é uma variável com relação de causa e efeito sobre PT, na qual poderia ser utilizada na seleção indireta de plantas mais produtivas de pimentão, obtidas a partir de sementes de alto vigor. As variáveis DC70 e DB90 também apresentaram maiores escores de correlações positivas $(0,51 \leq \mathrm{r} \leq$ $0,57)$ e efeitos diretos positivos sobre a produção total $(0,21 \leq$ efeito direto $\leq 0,30)$. Já as demais variáveis (AP50, AP70, AP90, AB50, AB90, DC50, DC90, DB70, PMF, CMF e LMF) apresentaram correlações positivas com a produção total de pimentão $(0,16 \leq \mathrm{r} \leq 0,52)$, sendo constatado efeitos diretos de baixa magnitude ou de sinal contrário a correlação ($0,18 \leq$ efeito direto $\leq 0,14)$, indicando a inexistência da relação causa e efeito sobre PT. Além disso, a maior parte da correlação obtida nestas variáveis com a PT foi explicada pelo efeito indireto via DB50 e em menor grau via DC70 e DB90 (Tabela 2). Dessa forma, verifica-se que o diâmetro da primeira bifurcação e o diâmetro do caule foram caracteres que influenciaram diretamente a produção de frutos, ou seja, plantas originadas de sementes de vigor alto que durante o seu desenvolvimento apresentem diâmetros maiores da primeira bifurcação aos 50 e 90 DAT e do caule aos 70 DAT tendem a ser mais produtivas.

Os caules de muitas plantas, incluindo o pimentão que é um arbusto perene, apresentam crescimento em diâmetro devido a ação dos meristemas laterais (câmbio vascular e felogênio). Portanto, o crescimento se deve a adição de novos tecidos ao corpo primário pela atividade do câmbio vascular. Com o aumento do volume do caule, a epiderme, tecido de revestimento do corpo primário, é substituída pela periderme, originada a partir do felogênio, ocorrendo o denominado crescimento secundário (CUTTER, 2002). Mediante a isso, a hipótese para os resultados obtidos provavelmente são em razão da maior translocação e acúmulo de matéria seca na parte aérea das plantas. Logo, o caule representa grande importância, constituindo em um condutor de água, sais minerais e substâncias nutritivas por toda a planta.
Em plantas originadas de sementes de vigor médio foram observadas correlações e efeitos diretos maiores de AP70 e DB90 sobre a produção total de frutos de pimentão. Com importância secundária, pode-se destacar o PMF, que também apresentou correlação $(0,38)$ e efeito direto positivo $(0,23)$ sobre PT (Tabela 3). As demais variáveis apresentaram efeitos diretos de baixa magnitude $(-0,16 \leq$ efeito direto $\leq 0,12)$ e, portanto, não apresentam relação de causa e efeito sobre a produção total de pimentão. Essas variáveis atuam de modo indireto sobre a produção total, especialmente via DB90 e AP70. Nas plantas originadas de sementes de vigor baixo verificou-se que as variáveis DC50, DC90, DB50 e LMF apresentaram correlações positivas e efeitos diretos de similar magnitude e mesma direção sobre a produção total de frutos, sendo essas variáveis diretamente envolvidas na obtenção de plantas mais produtivas (Tabela 4). No entanto, o coeficiente de determinação desta análise de trilha foi inferior aos obtidos nas análises de plantas originadas de sementes de vigor alto $\left(\mathrm{R}^{2}=0,52\right)$, vigor médio $\left(\mathrm{R}^{2}=0,44\right) \mathrm{e}$ vigor muito baixo $\left(\mathrm{R}^{2}=0,51\right)$, havendo menor poder preditivo com dados provenientes de plantas originadas de sementes de vigor baixo. Para as plantas originadas de sementes de vigor muito baixo os maiores efeitos diretos sobre a produção foram verificadas em PMF $(0,31)$ e $\operatorname{AP70}(0,26)$. As variáveis DB50, DB70, DB90 e AB50 também podem ser indicadoras de plantas mais produtivas, por possuírem correlação positiva e efeitos diretos de mesmo sinal, embora com magnitude inferior em relação a verificada nas variáveis AP70 e PMF (Tabela 5). O maior coeficiente de determinação obtido na análise de trilha com plantas de vigor muito baixo em relação ao vigor baixo pode estar relacionado ao uso de diferentes materiais genéticos (híbrido e cultivar) (Tabelas $4 \mathrm{e}$ $5)$.

Em estudos desenvolvidos por Carvalho et al. (1999) na cultura do pimentão os caracteres de maior importância sobre a produção de frutos corresponderam a altura de planta, largura do fruto e o peso médio dos frutos precoces. Em trabalhos com outras culturas agrícolas, Gomes e Lopes (2005) constataram que o rendimento de grãos de amendoim é influenciado positivamente pelo número de vagem por planta e do peso de cem grãos. Já Vieira et al. (2007) observaram os caracteres número de grãos por espigueta e número de afilhos por metro linear de maior importância na determinação do rendimento de trigo.

De modo geral, na estação de cultivo outonoinverno, os coeficientes de correlação obtidos entre as variáveis explicativas (AP50, AP70, AP90, AB50, AB90, DC50, DC70, DC90, DB50, DB70, DB90, PMF, CMF, LMF) e a produção total de pimentão foram baixos, não sendo identificada alta correlação com a produção (Tabelas 6 a 9). 
Tabela 6. Estimativa dos efeitos diretos e indiretos das variáveis explicativas sobre a produção total de frutos de pimentão (PT) provenientes de plantas originadas de sementes de vigor alto cultivadas em ambiente protegido na estação outonoinverno.

\begin{tabular}{|c|c|c|c|c|c|c|c|c|c|c|c|c|c|c|}
\hline \multirow{2}{*}{ Variáveis $^{1}$} & 50 & P70 & P90 & B50 & B90 & DC50 & $\mathrm{C} 70$ & DC90 & DB50 & DB70 & DB90 & PMF & CMF & LMF \\
\hline & \multicolumn{14}{|c|}{ Efeito indireto } \\
\hline Via AP50 & & $-0,06$ & $-0,06$ & $-0,03$ & $-0,02$ & $-0,05$ & $-0,05$ & $-0,05$ & $-0,06$ & $-0,03$ & $-0,03$ & $-0,02$ & 0,00 & 0,00 \\
\hline Via AP70 & 0,21 & & 0,23 & 0,13 & 0,11 & 0,13 & 0,13 & 0,14 & 0,14 & 0,11 & 0,11 & 0,09 & 0,01 & 0,03 \\
\hline Via AP90 & $-0,10$ & $-0,13$ & & $-0,07$ & $-0,05$ & $-0,07$ & $-0,07$ & $-0,08$ & $-0,07$ & $-0,06$ & $-0,07$ & $-0,06$ & $-0,01$ & $-0,02$ \\
\hline Via AB50 & 0,04 & 0,05 & 0,05 & & 0,08 & 0,02 & 0,04 & 0,04 & 0,02 & 0,03 & 0,02 & 0,03 & 0,00 & 0,01 \\
\hline Via AB90 & 0,00 & 0,00 & 0,00 & $-0,01$ & & 0,00 & 0,00 & 0,00 & 0,00 & 0,00 & 0,00 & 0,00 & 0,00 & 0,00 \\
\hline Via DC50 & 0,11 & 0,08 & 0,07 & 0,04 & 0,01 & & 0,12 & 0,12 & 0,13 & 0,08 & 0,07 & 0,04 & 0,02 & 0,04 \\
\hline Via DC70 & $-0,09$ & $-0,07$ & $-0,07$ & $-0,06$ & $-0,03$ & $-0,11$ & & $-0,12$ & $-0,10$ & $-0,09$ & $-0,07$ & $-0,05$ & $-0,02$ & $-0,03$ \\
\hline Via DC90 & 0,03 & 0,03 & 0,03 & 0,02 & 0,01 & 0,04 & 0,05 & & 0,04 & 0,04 & 0,03 & 0,01 & 0,01 & 0,01 \\
\hline Via DB50 & 0,16 & 0,11 & 0,09 & 0,04 & $-0,01$ & 0,17 & 0,15 & 0,14 & & 0,13 & 0,09 & 0,05 & 0,00 & 0,04 \\
\hline Via DB70 & 0,06 & 0,07 & 0,07 & 0,04 & 0,01 & 0,09 & 0,10 & 0,10 & 0,10 & & 0,11 & 0,03 & 0,01 & 0,05 \\
\hline Via D & 0,05 & 0,06 & 0,07 & 0,04 & 0,02 & 0,06 & 0,07 & 0,09 & 0,07 & 0,10 & & 0,01 & 0,03 & 0,02 \\
\hline Via PMF & 0,08 & 0,11 & 0,13 & 0,09 & 0,05 & 0,07 & 0,10 & 0,08 & 0,07 & 0,06 & 0,02 & & 0,02 & 0,17 \\
\hline Via CMF & 0,00 & 0,00 & 0,00 & 0,00 & 0,00 & 0,00 & 0,00 & 0,00 & 0,00 & 0,00 & $-0,01$ & 0,00 & & 0,00 \\
\hline Via LMF & 0,00 & 0,00 & 0,00 & 0,00 & 0,00 & 0,01 & 0,01 & 0,00 & 0,01 & 0,01 & 0,00 & 0,02 & 0,00 & \\
\hline Efeito direto & $-0,08$ & 0,26 & $-0,15$ & 0,10 & $-0,01$ & 0,16 & $-0,15$ & 0,05 & 0,21 & 0,16 & 0,15 & 0,31 & $-0,03$ & 0,03 \\
\hline Correlação $^{3}$ & $0,46^{*}$ & $0,50^{*}$ & $0,46^{*}$ & $0,33^{*}$ & $0,17^{\mathrm{ns}}$ & $0,51^{*}$ & $0,49^{*}$ & $0,51^{*}$ & $0,54^{*}$ & $0,54^{*}$ & $0,45^{*}$ & $0,46^{*}$ & $0,05^{\mathrm{ns}}$ & $0,35^{*}$ \\
\hline $\mathrm{R}^{2}$ & 0,51 & & & & & & & & & & & & & \\
\hline
\end{tabular}

${ }^{1}$ AP50, AP70 e AP90: altura de plantas aos 50, 70 e 90 dias após o transplantio (DAT), respectivamente; AB50 e AB90: altura da primeira bifurcação aos 50 e 90 dias após o transplantio (DAT), respectivamente; DC50, DC70 e DC90: diâmetro do caule aos 50, 70 e 90 dias após o transplantio (DAT), respectivamente; DB50, DB70 e DB90: diâmetro abaixo da primeira bifurcação aos 50,70 e 90 dias após o transplantio (DAT), respectivamente; PMF: peso médio de frutos; CMF: comprimento médio de frutos; e LMF: largura média de frutos.

${ }^{3}:{ }^{n s} \mathrm{e}^{*}$, significativo a $5 \%$ de probabilidade pelo teste $\mathrm{t}$, respectivamente.

${ }^{2}$ Coeficiente de determinação.

Tabela 7. Estimativa dos efeitos diretos e indiretos das variáveis explicativas sobre a produção total de frutos de pimentão (PT) provenientes de plantas originadas de sementes de vigor médio cultivadas em ambiente protegido na estação outonoinverno.

\begin{tabular}{|c|c|c|c|c|c|c|c|c|c|c|c|c|c|c|}
\hline \multirow{2}{*}{ Variáveis ${ }^{1}$} & AP50 & AP70 & AP90 & AB50 & AB90 & DC50 & DC70 & DC90 & DB50 & DB70 & DB90 & PMF & $\mathrm{CMF}$ & LMF \\
\hline & \multicolumn{14}{|c|}{ Efeito indireto } \\
\hline Via AP50 & & $-0,06$ & $-0,06$ & $-0,03$ & $-0,02$ & $-0,05$ & $-0,05$ & $-0,05$ & $-0,06$ & $-0,03$ & $-0,03$ & $-0,02$ & 0,00 & 0,00 \\
\hline Via AP70 & 0,21 & & 0,23 & 0,13 & 0,11 & 0,13 & 0,13 & 0,14 & 0,14 & 0,11 & 0,11 & 0,09 & 0,01 & 0,03 \\
\hline Via AP90 & $-0,10$ & $-0,13$ & & $-0,07$ & $-0,05$ & $-0,07$ & $-0,07$ & $-0,08$ & $-0,07$ & $-0,06$ & $-0,07$ & $-0,06$ & $-0,01$ & $-0,02$ \\
\hline Via AB50 & 0,04 & 0,05 & 0,05 & & 0,08 & 0,02 & 0,04 & 0,04 & 0,02 & 0,03 & 0,02 & 0,03 & 0,00 & 0,01 \\
\hline Via AB90 & 0,00 & 0,00 & 0,00 & $-0,01$ & & 0,00 & 0,00 & 0,00 & 0,00 & 0,00 & 0,00 & 0,00 & 0,00 & 0,00 \\
\hline Via DC50 & 0,11 & 0,08 & 0,07 & 0,04 & 0,01 & & 0,12 & 0,12 & 0,13 & 0,08 & 0,07 & 0,04 & 0,02 & 0,04 \\
\hline Via DC70 & $-0,09$ & $-0,07$ & $-0,07$ & $-0,06$ & $-0,03$ & $-0,11$ & & $-0,12$ & $-0,10$ & $-0,09$ & $-0,07$ & $-0,05$ & $-0,02$ & $-0,03$ \\
\hline Via DC90 & 0,03 & 0,03 & 0,03 & 0,02 & 0,01 & 0,04 & 0,05 & & 0,04 & 0,04 & 0,03 & 0,01 & 0,01 & 0,01 \\
\hline Via DB50 & 0,16 & 0,11 & 0,09 & 0,04 & $-0,01$ & 0,17 & 0,15 & 0,14 & & 0,13 & 0,09 & 0,05 & 0,00 & 0,04 \\
\hline Via DB70 & 0,06 & 0,07 & 0,07 & 0,04 & 0,01 & 0,09 & 0,10 & 0,10 & 0,10 & & 0,11 & 0,03 & 0,01 & 0,05 \\
\hline Via DB90 & 0,05 & 0,06 & 0,07 & 0,04 & 0,02 & 0,06 & 0,07 & 0,09 & 0,07 & 0,10 & & 0,01 & 0,03 & 0,02 \\
\hline Via PMF & 0,08 & 0,11 & 0,13 & 0,09 & 0,05 & 0,07 & 0,10 & 0,08 & 0,07 & 0,06 & 0,02 & & 0,02 & 0,17 \\
\hline Via CMF & 0,00 & 0,00 & 0,00 & 0,00 & 0,00 & 0,00 & 0,00 & 0,00 & 0,00 & 0,00 & $-0,01$ & 0,00 & & 0,00 \\
\hline Via LMF & 0,00 & 0,00 & 0,00 & 0,00 & 0,00 & 0,01 & 0,01 & 0,00 & 0,01 & 0,01 & 0,00 & 0,02 & 0,00 & \\
\hline Efeito direto & $-0,08$ & 0,26 & $-0,15$ & 0,10 & $-0,01$ & 0,16 & $-0,15$ & 0,05 & 0,21 & 0,16 & 0,15 & 0,31 & $-0,03$ & 0,03 \\
\hline Correlação $^{3}$ & $0,46^{*}$ & $0,50^{*}$ & $0,46^{*}$ & $0,33^{*}$ & $0,17^{\mathrm{ns}}$ & $0,51^{*}$ & $0,49^{*}$ & $0,51^{*}$ & $0,54^{*}$ & $0,54^{*}$ & $0,45^{*}$ & $0,46^{*}$ & $0,05^{\mathrm{ns}}$ & $0,35^{*}$ \\
\hline $\mathrm{R}^{2}$ & 0,51 & & & & & & & & & & & & & \\
\hline
\end{tabular}

${ }^{1}$ AP50, AP70 e AP90: altura de plantas aos 50, 70 e 90 dias após o transplantio (DAT), respectivamente; AB50 e AB90: altura da primeira bifurcação aos 50 e 90 dias após o transplantio (DAT), respectivamente; DC50, DC70 e DC90: diâmetro do caule aos 50,70 e 90 dias após o transplantio (DAT), respectivamente; DB50, DB70 e DB90: diâmetro abaixo da primeira bifurcação aos 50,70 e 90 dias após o transplantio (DAT), respectivamente; PMF: peso médio de frutos; CMF: comprimento médio de frutos; e LMF: largura média de frutos.

$3 \mathrm{~ns} \mathrm{e}^{*}$, significativo a $5 \%$ de probabilidade pelo teste $\mathrm{t}$, respectivamente.

${ }^{2}$ Coeficiente de determinação.

Revista Caatinga, Mossoró, v. 28, n. 3, p. 108 - 118, jul. - set., 2015 
Tabela 8. Estimativa dos efeitos diretos e indiretos das variáveis explicativas sobre a produção total de frutos de pimentão (PT) provenientes de plantas originadas de sementes de vigor baixo cultivada em ambiente protegido na estação outonoinverno.

\begin{tabular}{|c|c|c|c|c|c|c|c|c|c|c|c|c|c|c|}
\hline \multirow{2}{*}{ Variáveis ${ }^{1}$} & 0 & AP70 & $\mathrm{P} 90$ & B50 & AB90 & DC50 & DC70 & DC90 & DB50 & DB70 & DB90 & PMF & $\mathrm{CMF}$ & LMF \\
\hline & \multicolumn{14}{|c|}{ Efeito indireto } \\
\hline Via AP50 & & $-0,06$ & $-0,06$ & $-0,03$ & $-0,02$ & $-0,05$ & $-0,05$ & $-0,05$ & $-0,06$ & $-0,03$ & $-0,03$ & $-0,02$ & 0,00 & 0,00 \\
\hline Via AP70 & 0,21 & & 0,23 & 0,13 & 0,11 & 0,13 & 0,13 & 0,14 & 0,14 & 0,11 & 0,11 & 0,09 & 0,01 & 0,03 \\
\hline Via AP90 & $-0,10$ & $-0,13$ & & $-0,07$ & $-0,05$ & $-0,07$ & $-0,07$ & $-0,08$ & $-0,07$ & $-0,06$ & $-0,07$ & $-0,06$ & $-0,01$ & $-0,02$ \\
\hline Via AB50 & 0,04 & 0,05 & 0,05 & & 0,08 & 0,02 & 0,04 & 0,04 & 0,02 & 0,03 & 0,02 & 0,03 & 0,00 & 0,01 \\
\hline Via AB90 & 0,00 & 0,00 & 0,00 & $-0,01$ & & 0,00 & 0,00 & 0,00 & 0,00 & 0,00 & 0,00 & 0,00 & 0,00 & 0,00 \\
\hline Via DC50 & 0,11 & 0,08 & 0,07 & 0,04 & 0,01 & & 0,12 & 0,12 & 0,13 & 0,08 & 0,07 & 0,04 & 0,02 & 0,04 \\
\hline & $-0,09$ & $-0,07$ & $-0,07$ & $-0,06$ & $-0,03$ & $-0,11$ & & $-0,12$ & $-0,10$ & $-0,09$ & $-0,07$ & $-0,05$ & $-0,02$ & $-0,03$ \\
\hline Via DC90 & 0,03 & 0,03 & 0,03 & 0,02 & 0,01 & 0,04 & 0,05 & & 0,04 & 0,04 & 0,03 & 0,01 & 0,01 & 0,01 \\
\hline Via DB50 & 0,16 & 0,11 & 0,09 & 0,04 & $-0,01$ & 0,17 & 0,15 & 0,14 & & 0,13 & 0,09 & 0,05 & 0,00 & 0,04 \\
\hline Via DB70 & 0,06 & 0,07 & 0,07 & 0,04 & 0,01 & 0,09 & 0,10 & 0,10 & 0,10 & & 0,11 & 0,03 & 0,01 & 0,05 \\
\hline Via DB90 & 0,05 & 0,06 & 0,07 & 0,04 & 0,02 & 0,06 & 0,07 & 0,09 & 0,07 & 0,10 & & 0,01 & 0,03 & 0,02 \\
\hline Via PMF & 0,08 & 0,11 & 0,13 & 0,09 & 0,05 & 0,07 & 0,10 & 0,08 & 0,07 & 0,06 & 0,02 & & 0,02 & 0,17 \\
\hline Via CMF & 0,00 & 0,00 & 0,00 & 0,00 & 0,00 & 0,00 & 0,00 & 0,00 & 0,00 & 0,00 & $-0,01$ & 0,00 & & 0,00 \\
\hline Via LMF & 0,00 & 0,00 & 0,00 & 0,00 & 0,00 & 0,01 & 0,01 & 0,00 & 0,01 & 0,01 & 0,00 & 0,02 & 0,00 & \\
\hline Efeito direto & $-0,08$ & 0,26 & $-0,15$ & 0,10 & $-0,01$ & 0,16 & $-0,15$ & 0,05 & 0,21 & 0,16 & 0,15 & 0,31 & $-0,03$ & 0,03 \\
\hline Correlação $^{3}$ & $0,46^{*}$ & $0,50^{*}$ & $0,46^{*}$ & $0,33^{*}$ & $0,17^{\mathrm{ns}}$ & $0,51^{*}$ & $0,49^{*}$ & $0,51^{*}$ & $0,54^{*}$ & $0,54^{*}$ & $0,45^{*}$ & $0,46^{*}$ & $0,05^{\mathrm{ns}}$ & $0,35^{*}$ \\
\hline $\mathrm{R}^{2}$ & 0,51 & & & & & & & & & & & & & \\
\hline
\end{tabular}

${ }^{1}$ AP50, AP70 e AP90: altura de plantas aos 50, 70 e 90 dias após o transplantio (DAT), respectivamente; AB50 e AB90: altura da primeira bifurcação aos 50 e 90 dias após o transplantio (DAT), respectivamente; DC50, DC70 e DC90: diâmetro do caule aos 50, 70 e 90 dias após o transplantio (DAT), respectivamente; DB50, DB70 e DB90: diâmetro abaixo da primeira bifurcação aos 50,70 e 90 dias após o transplantio (DAT), respectivamente; PMF: peso médio de frutos; CMF: comprimento médio de frutos; e LMF: largura média de frutos.

${ }^{3}:$ ns $\mathrm{e} *$, significativo a $5 \%$ de probabilidade pelo teste t, respectivamente.

${ }^{2}$ Coeficiente de determinação.

Tabela 9. Estimativa dos efeitos diretos e indiretos das variáveis explicativas sobre a produção total de frutos de pimentão (PT) provenientes de plantas originadas de sementes de vigor muito baixo cultivadas em ambiente protegido na estação outono-inverno.

\begin{tabular}{|c|c|c|c|c|c|c|c|c|c|c|c|c|c|c|}
\hline \multirow{2}{*}{ Variáveis ${ }^{1}$} & P50 & AP70 & AP90 & AB50 & AB90 & DC50 & DC70 & DC90 & DB50 & DB70 & DB90 & PMF & CMF & LMF \\
\hline & \multicolumn{14}{|c|}{ Efeito indireto } \\
\hline Via AP50 & & 0,00 & 0,00 & 0,00 & 0,00 & 0,00 & 0,00 & 0,00 & 0,00 & 0,00 & 0,00 & 0,00 & 0,00 & 0,00 \\
\hline Via AP70 & $-0,10$ & & $-0,12$ & $-0,06$ & $-0,01$ & $-0,02$ & $-0,01$ & $-0,01$ & $-0,07$ & $-0,06$ & $-0,05$ & $-0,05$ & $-0,04$ & $-0,02$ \\
\hline Via AP90 & 0,19 & 0,22 & & 0,09 & 0,03 & 0,04 & 0,01 & 0,02 & 0,13 & 0,11 & 0,10 & 0,06 & 0,05 & 0,02 \\
\hline Via AB50 & 0,06 & 0,06 & 0,05 & & 0,06 & $-0,01$ & 0,01 & 0,01 & 0,04 & 0,05 & 0,04 & 0,03 & 0,01 & 0,01 \\
\hline Via AB90 & 0,00 & $-0,02$ & $-0,02$ & $-0,07$ & & 0,03 & 0,01 & $-0,01$ & 0,01 & $-0,01$ & $-0,01$ & 0,01 & 0,02 & $-0,01$ \\
\hline Via DC50 & 0,00 & 0,00 & 0,00 & 0,00 & 0,00 & & 0,01 & 0,01 & 0,01 & 0,01 & 0,00 & 0,00 & 0,00 & 0,00 \\
\hline Via DC70 & 0,01 & 0,00 & 0,00 & 0,01 & $-0,01$ & 0,07 & & 0,06 & 0,03 & 0,03 & 0,02 & 0,01 & 0,01 & 0,02 \\
\hline Via DC90 & 0,05 & 0,02 & 0,02 & 0,02 & 0,01 & 0,14 & 0,14 & & 0,07 & 0,07 & 0,07 & 0,02 & 0,00 & 0,01 \\
\hline Via DB50 & 0,22 & 0,18 & 0,18 & 0,09 & $-0,02$ & 0,15 & 0,12 & 0,12 & & 0,29 & 0,24 & 0,09 & 0,04 & 0,05 \\
\hline Via DB70 & $-0,11$ & $-0,09$ & $-0,09$ & $-0,07$ & $-0,01$ & $-0,09$ & $-0,07$ & $-0,07$ & $-0,17$ & & $-0,16$ & $-0,04$ & $-0,02$ & $-0,04$ \\
\hline Via DB90 & $-0,01$ & $-0,01$ & $-0,01$ & $-0,01$ & 0,00 & $-0,01$ & $-0,01$ & $-0,01$ & $-0,01$ & $-0,02$ & & $-0,01$ & 0,00 & 0,00 \\
\hline Via PMF & 0,04 & 0,04 & 0,03 & 0,02 & $-0,01$ & 0,02 & 0,01 & 0,01 & 0,03 & 0,02 & 0,03 & & 0,07 & 0,07 \\
\hline Via CMF & 0,01 & 0,01 & 0,01 & 0,00 & 0,00 & 0,00 & 0,00 & 0,00 & 0,00 & 0,00 & 0,00 & 0,02 & & 0,01 \\
\hline Via LMF & 0,00 & $-0,01$ & 0,00 & 0,00 & 0,00 & $-0,01$ & $-0,01$ & 0,00 & $-0,01$ & $-0,01$ & $-0,01$ & $-0,04$ & $-0,02$ & \\
\hline Efeito direto & 0,00 & $-0,14$ & 0,26 & 0,14 & $-0,16$ & 0,01 & 0,09 & 0,21 & 0,35 & $-0,20$ & $-0,02$ & 0,12 & 0,03 & $-0,06$ \\
\hline Correlação $^{3}$ & $0,35^{*}$ & $0,27^{*}$ & $0,31^{*}$ & $0,17^{\mathrm{ns}}$ & $-0,13^{\mathrm{ns}}$ & $0,33^{*}$ & $0,32^{*}$ & $0,34^{*}$ & $0,41^{*}$ & $0,28^{*}$ & $0,26^{*}$ & $0,24^{*}$ & $0,16^{\mathrm{ns}}$ & $0,05^{\text {ns }}$ \\
\hline $\mathrm{R}^{2}$ & 0,30 & & & & & & & & & & & & & \\
\hline
\end{tabular}

${ }^{1}$ AP50, AP70 e AP90: altura de plantas aos 50, 70 e 90 dias após o transplantio (DAT), respectivamente; AB50 e AB90: altura da primeira bifurcação aos 50 e 90 dias após o transplantio (DAT), respectivamente; DC50, DC70 e DC90: diâmetro do caule aos 50, 70 e 90 dias após o transplantio (DAT), respectivamente; DB50, DB70 e DB90: diâmetro abaixo da primeira bifurcação aos 50,70 e 90 dias após o transplantio (DAT), respectivamente; PMF: peso médio de frutos; CMF: comprimento médio de frutos; e LMF: largura média de frutos.

${ }^{3}:{ }^{n s} \mathrm{e}^{*}$, significativo a $5 \%$ de probabilidade pelo teste $\mathrm{t}$, respectivamente.

${ }^{2}$ Coeficiente de determinação. 
Foram constatados, também, efeitos diretos de baixa magnitude e oscilações de valores positivos e negativos para a maioria das variáveis em todos os níveis de vigor avaliados, não apresentando relação de causa e efeito com a produção total de frutos. Como consequência, o efeito preditivo da análise de trilha nos quatro níveis de vigor foi reduzido, entre $0,19 \leq \mathrm{R}^{2} \leq 0,30$, indicando que a produção total de frutos não pode ser explicada satisfatoriamente com as variáveis explicativas utilizadas no presente estudo (Tabelas 6 a 9).

Os resultados obtidos na estação outonoinverno se devem a alta variabilidade existente na estação de cultivo outono-inverno, na qual foram verificados coeficientes de variação oscilando em intensidade de $6,17 \% \leq \mathrm{CV} \leq 65,22 \%$ (dados não apresentados), justificado pelo efeito sucessivo das colheitas e pelas condições ambientais adversas. Isso leva a variabilidade muito alta, refletindo desde o momento do transplante de mudas até a produção final. Neste sentido, pode-se destacar que as mudas transplantadas no outono-inverno foram expostas a condições ambientais mais extremas em relação às transplantadas na primavera-verão, especialmente em relação às oscilações entre temperaturas altas e baixas, decréscimo da intensidade luminosa e umidade relativa do ar no início do desenvolvimento das plantas. Portanto, espera-se que as variações ambientais incidentes no início da fase de crescimento e desenvolvimento das plantas logo após o transplante possam contribuir para o aumento da variabilidade dos caracteres mensurados aos 50, 70 e 90 dias após o transplante e na produção total de frutos de pimentão. Dessa forma, as relações existentes entre as variáveis podem sofrer alterações e, possivelmente, maior tamanho de amostra seja necessário para detectar as reais relações lineares existentes entre os caracteres nessa condição ambiental.

\section{CONCLUSÕES}

Existe variabilidade das relações lineares entre caracteres de pimentão provenientes de sementes com diferentes níveis de qualidade fisiológica, épocas de cultivo e cultivares.

As plantas obtidas a partir de sementes de vigor alto, médio e baixo com maior diâmetro da primeira bifurcação aos 50 e 90 dias após o transplantio são mais produtivas na estação de cultivo primavera-verão.

Há fraca relação de causa e efeito das variáveis morfológicas e produtivas de plantas de pimentão originadas de sementes de vigor alto, médio, baixo e muito baixo sobre a produção total de frutos na estação de cultivo outono-inverno.
À FAPERGS, a Capes e ao CNPq pelo auxílio financeiro e pelas concessões das bolsas de doutorado e de Produtividade em Pesquisa.

\section{REFERÊNCIAS}

BRASIL. Ministério da Agricultura, Pecuária e Abastecimento. Regras para análise de sementes. Brasília: MAPA/ACS, 2009. 395 p.

CARGNELUTTI FILHO, A. et al. Número necessário de experimentos para análise de trilha em feijão. Ciência Rural, Santa Maria, v. 41, n. 4, p. 564-572, 2011.

CARVALHO, S. P. Métodos alternativos de estimação de coeficientes de trilha e índices de seleção, sob multicolinearidade. Viçosa: UFV, 1995. $163 \mathrm{p}$.

CARVAlHO, C. G. P. et al. Análise de trilha sob multicolinearidade em pimentão. Pesquisa Agropecuária Brasileira, Brasília, v. 34, n. 4, p. 603-613, 1999.

CRUZ, C. D.; REGAZZI, A. J. Modelos biométricos aplicados ao melhoramento genético. 2.ed. Viçosa: UFV, 1997. 390 p.

CRUZ, C. D. GENES - a software package for analysis in experimental statistics and quantitative genetics. Acta ScientiarumAgronomy, Maringá, v. 35, n. 3, p. 271-276, 2013.

CRUZ, C. D.; CARNEIRO, P. C. S. Modelos biométricos aplicados ao melhoramento genético. 2.ed. Viçosa: UFV, 2006.v. 2. 585p.

CUTTER, E. G. Anatomia vegetal. Parte II. Orgãos -experimentos e interpretação. São Paulo: Roca Editora, $2002.336 \mathrm{p}$.

DANTAS, M. R. S.; TORRES, S. B. Vigor de sementes de rúcula e desempenho das plantas em campo. Revista Brasileira de Sementes, Londrina, v. 32, n. 4, p. 49-57, 2010

GAMIELY, S.; SMitTle, D. A.; MILLS, H. A. Onion seed size, weight and elemental content affect germination an bulb yield. Hortscience, Alexandria, v. 25, n. 5, p. 522-523, 1990.

GOMES, R. L. F.; LOPES, A. C. A. Correlations and path analysis in peanut. Crop Breeding and Applied Biotechnology, Viçosa, v. 5, n. 1, p. 105112, 2005.

\section{AGRADECIMENTOS}


GOULART, L. S.; TILLMANN, M. A. A. Vigor de sementes de rúcula (Eruca sativa L.) pelo teste de deterioração controlada. Revista Brasileira de Sementes, Londrina, v. 29, n. 2, p. 179-186, 2007.

KIKUTI, A. L. P.; MARCOS FILHO, J. Potencial fisiológico de sementes de couve-flor e desempenho das plantas em campo. Revista Brasileira de Sementes, Londrina, v. 29, n. 1, p. 107-113, 2007.

LÚCIO, A. D. et al. Variação temporal da produção de pimentão influenciada pela posição e características morfológicas das plantas em ambiente protegido. Horticultura Brasileira, Brasília, v. 24, n. 1, p. 3135, 2006.

LÚCIO, A. D. et al. Relações entre os caracteres de maracujazeiro-azedo. Ciência Rural, Santa Maria, v. 43, n. 2, p. 225-232, 2013.

MAGUIRE, J. D. Speed of germination-aid in selection and evaluation for seedling emergence and vigor. Crop Science, Madison, v. 2, n. 1, p. 176-177, 1962.

MARCOS FILHO, J. Teste de envelhecimento acelerado. In: KRZYZANOWSKI, F. C.; VIEIRA, R. D.; FRANÇA NETO, J. B. (Ed.) Vigor de sementes: conceitos e testes. Londrina: ABRATES, 1999. p. 3.1-3.24.

MONTGOMERY, D. C.; PECK, E. A. Introduction to linear regression analysis. New York: John Wiley e Sons, 1982. 504 p.

SANTOS, C. M. R. et al. Alterações fisiológicas e bioquímicas em sementes de feijão envelhecidas artificialmente. Revista Brasileira de Sementes, Londrina, v. 26, n. 1, p. 110-119, 2004.

TOEBE, M.; CARGNELUTTI FILHO, A. Não normalidade multivariada e multicolinearidade na análise de trilha em milho. Pesquisa AgropecuáriaBrasileira, Brasília, v. 48, n. 5, p. 466-477, 2013.

VIEIRA, E. A.et al. Análise de trilha entre os componentes primários e secundários do rendimento de grãos em trigo. Revista Brasileira de Agrociência, Pelotas, v. 13, n. 2, p. 169-174, 2007.

WRIGHT, S.Correlationandcausation. Journal of Agricultural Research,Washington, v. 20, n. 7, p. 557-585, 1921.
WRIGHT, S. The theory of path coefficients - a replay to Niles' criticism. Genetics, Austin, v. 52, n. 3, p. 239-255, 1923. 